\title{
PRODUÇÃO DE MAPAS DIGITALIZADOS E BANCO DE DADOS PARA GEOPROCESSAMENTO FL.ITARARÉ (SG22-X-B-1:250.000)
}

\author{
A.B.Macedo' \\ G.A.C.Campanha ${ }^{2}$ \\ M.A.Braghin ${ }^{1}$ \\ C.C.Araújo ${ }^{1}$
}

A área da folha Itararé (SG22-X-B-1:250.000) apresenta terrenos da planície costeira aos planaltos de SP e PR, parcialmente cobertos pela Mata Atlântica, com rochas complexamente tectonizadas, de idades do Arqueano ao Recente, sendo em sua maioria proterozóicas da Faixa de Dobramentos Ribeira. Seus principais recursos minerais incluem chumbo, prata, ouro, cobre, zinco, fluorita, barita, calcário e granito. A avaliação do potencial mineral é decisiva para o planejamento do aproveitamento mineral e a destinação de áreas para preservação na região.

A quadrícula de Itararé a 1:250.000 foi escolhida para a montagem de um Sistema de Informações Georeferenciadas (SIG), com objetivos práticos (avaliação do potencial mineral e de impacto ambiental da mineração) e didáticos (incorporação das técnicas de produção de mapas digitalizados e banco de dados, e de análise por geoprocessamento, com difusão destas técnicas entre os profissionais do IG-USP e IPT e em cursos para alunos de graduação e pós-graduação). Foram digitalizados os mapas: Topográficos, segundo o mapa-base do IBGE, para relevo, hidrologia e estradas; geológicos: com litologia, diques, falhas, em duas versões: segundo o projeto Mapas Metalogenéticos e Previsionais (Algarte et al., 1984) e segundo a nova síntese geológica em elaboração pela equipe do IPT (inédita), ocorrências minerais: usando os arquivos elaborados pela CPRM, MINEROPAR e IG-UNICAMP (IDEM), anomalias geoquímicas e geofísicas (segundo Algarte et al., 1984), encontrando-se em elaboração os mapas de vegetação, com dados de sensoriamento remoto e de áreas protegidas, com dados da Secretaria do Meio Ambiente de São Paulo e da SUREHMA, Paraná.

Para a seleção do SIG foram levados em conta os seguintes parâmetros: o sistema deve ser aberto, em programas e dados, para atualização e novas aplicações; deve ter capacidade para utilização em diversos graus de complexidade: captura e edição de mapas, banco de dados,

\footnotetext{
${ }^{1}$ Departamento de Geologia Econరిmica e Geofísica Aplicada, Instituto de Geociências, USP.

${ }^{2}$ Instituto de Pesquisas Tecnologicas.
} 
manipulação e análise, desde superposição a uso de Inteligência Artificial para avaliação mineral e ambiental; deve ser de baixo custo, operar em computador de pequeno porte (sob MS-DOS, com vídeo VGA) e ser utilizável, com pouco treinamento, para aulas de graduação. A seleção inicial foi efetuada comparando programas disponiveis na Colorado School of Mines e que pudessem também ser utilizados no IG-USP: destes o ARC/INFO (Environmental Systems Research Institute, Inc.) apresenta boa capacidade de edição, mas não dispõe de instrumentos de análise adequados à avaliação, além de ter alto custo e exigir estação UNIX; ILWIS era de baixo custo, e tinha melhor capacidade de análise, mas apresentava problemas para edição; o IDRISI (Clark University), de custo muito inferior aos anteriores, tem na versão 4 capacidade de edição e análise suficientes e pode ser facilmente utilizado para ensino. Seus problemas para produção de mapas finais são contornados pela conversão dos produtos para programas de desenho e edição (Photostyler e Paintbrush). Foi inicialmente decidida a utilização de ARC/INFO para edição dos mapas e de IDRISI para análise.

Foi inicialmente testado o processo padrão do USGS/CSM: captura de dados por scanner em overlays unitemáticos, edição em ARC/INFO, produção de MNT e conversão dos arquivos para ILWIS e IDRISI; este processo exige trabalho igual à digitalização manual, sem a edição instantânea inerente a esta; novos mapas serão digitalizados manualmente, até que melhores equipamentos e programas sejam disponíveis. O ILWIS revelou-se pouco prático, não sendo mais planejada sua aquisição pelo IG-USP.

O sistema foi utilizado para avaliação preliminar de recursos minerais da folha de Itararé, na CSM e no CIMRI/USGS, usando IDRISI para conversão do banco de dados e geoprocessamento. Para continuidade do trabalho foi utilizado o sistema AUTOCAD (Autodesk, Inc.) para digitalização manual dos novos mapas geológicos, aproveitando a disponibilidade de programas e prática na sua utilização no IG-USP e no IPT, fazendo a conversão para IDRISI para análise. Na continuidade do trabalho o AUTTOCAD deve ser utilizado para produção final de mapas. Os programas de desenho estão sendo utilizados para a produção de figuras de pequeno porte para ilustração de relatórios.

\section{REFERÊNCIAS BIBLIOGRÁFICAS}

Algarte, J.P. et al. (1984) Folha Itararé. Projeto Mapas Metalogenéticos e de Previsão de Recursos Minerais. Relatório Final. São Paulo, DNPM/CPRM , 1984, 61 p. 